\title{
Poor self-rated health predicts the incidence of functional disability in elderly community dwellers in Japan: a prospective cohort study
}

Shuko Takahashi ${ }^{1,2,3^{*}}$ D, Kozo Tanno ${ }^{4}$, Yuki Yonekura ${ }^{5}$, Masaki Ohsawa ${ }^{6}$, Toru Kuribayashi ${ }^{7}$, Yasuhiro Ishibashi ${ }^{8}$, Shinichi Omama9 ${ }^{9}$, Fumitaka Tanaka ${ }^{10}$, Ryohei Sasaki ${ }^{4}$, Megumi Tsubota-Utsugi ${ }^{4}$, Eri Takusari ${ }^{4}$, Makoto Koshiyama ${ }^{11}$, Toshiyuki Onoda ${ }^{12}$, Kiyomi Sakata ${ }^{4}$, Kazuyoshi Itai ${ }^{13}$, Akira Okayama ${ }^{14}$ and on behalf of the Iwate KENCO study group

\begin{abstract}
Background: Although previous large population studies showed elderly with poor self-rated health (SRH) to be at a high risk of functional disability in Western countries, there have been few studies in which the association between SRH and functional disability was investigated in Japanese community dwellers. The association between $\mathrm{SRH}$ and functional disability, defined as certification of the long-term care insurance (LTCI) system, in Japanese elderly community dwellers was examined in this study.
\end{abstract}

Methods: A total of 10,690 individuals (39.5\% men, mean age of 71.4 years) who were 65 years of age or more who did not have a history of cardiovascular disease or $\mathrm{LTCl}$ certification were followed in this prospective study for 10.5 years. SRH was classified into four categories: good, rather good, neither good nor poor, and poor. A Cox proportional-hazards model was used to determine the hazard ratios (HRs) for the incidence of functional disability among the SRH groups for each sex.

Results: The number of individuals with functional disability was 3377. Men who rated poor for SRH scored significantly higher for functional disability (HR [95\% confidence interval]: poor $=1.74[1.42,2.14]$ ) while women who rated rather good, neither good nor poor, and poor scored significantly higher for functional disability (rather good $=1.12[1.00,1.25]$, neither good nor poor $=1.29[1.13,1.48]$, poor $=1.92[1.65,2.24]$ : $p$ for trend $<0.001$ in both sexes).

Conclusion: Self-rated health, therefore, might be a useful predictor of functional disability in elderly people.

Keywords: Aged, Japan, Long-term care insurance, Subjective health, Functional disability, Self-rated health

* Correspondence: shutakahashi-iwt@umin.ac.jp

'Division of Medical Education, Iwate Medical University, Idaidori 1-1-1, Yahaba-Cho, Shiwa-gun, Iwate 028-3694, Japan

${ }^{2}$ Department of Health and Welfare, Iwate Prefecture, Morioka, Iwate, Japan Full list of author information is available at the end of the article

\section{Background}

It has been reported that poor self-rated health (SRH) is an indication of underlying physical and mental abnormalities that are often difficult to detect through other measures of health such as body weight and blood pressure [1]. Previous studies have shown that poor SRH is associated with mortality [2], morbidity (e.g.,

C C The Author(s). 2020 Open Access This article is licensed under a Creative Commons Attribution 4.0 International License, which permits use, sharing, adaptation, distribution and reproduction in any medium or format, as long as you give appropriate credit to the original author(s) and the source, provide a link to the Creative Commons licence, and indicate if changes were made. The images or other third party material in this article are included in the article's Creative Commons licence, unless indicated otherwise in a credit line to the material. If material is not included in the article's Creative Commons licence and your intended use is not permitted by statutory regulation or exceeds the permitted use, you will need to obtain permission directly from the copyright holder. To view a copy of this licence, visit http://creativecommons.org/licenses/by/4.0/ The Creative Commons Public Domain Dedication waiver (http://creativecommons.org/publicdomain/zero/1.0/) applies to the data made available in this article, unless otherwise stated in a credit line to the data. 
cardiovascular disease) [3, 4], cancer [5], musculoskeletal disease [6], psychiatric diseases [7], and dementia [8].

The proportions of elderly people over the age of 65 years in populations have recently been increasing [9]. The government and private sector will both need to deal with these situations by addressing new approaches to social security. Japan has achieved the highest longevity ratings in the world ( 81 years of age for men and 87 years of age for women) [10], and the proportion of people aged 65 years or older is estimated to be 35.6 million $(28.1 \%$ of the population) [11]. By 2042, it is predicted that the number of elderly people in Japan will reach 38.9 million [12]. There is an ongoing issue about sustaining senior health using social security in order to balance the financial burdens of pension and health care expenditure [13].

In 2000, the Japanese government implemented a long-term care insurance (LTCI) system for elderly individuals [14]. In 2016, the number of individuals using this service was approximately 6.3 million, which was 2.9-times larger than the number of initial certificates in 2000 [15]. Since the number of candidates is increasing, there is an urgent need to take measures of prevention in order to aid disability and intervene for those at high risk for various diseases, which in turn would prevent an increase in the financial burden.

Various endpoints including activities of daily living (ADL), basic ADL, LTCI, and independent criteria were used in previous studies. The studies mentioned above had small numbers of subjects (subjects ranging from 165 to 737) [16-18] except for one study [19]. Furthermore, the follow-up periods of the surveys conducted in those studies were also relatively short. The follow-up period in one study was only 1 year [18], while the follow-up periods after the baseline surveys were 5 years in the other studies [16, $17,19]$. To the best of our knowledge, there has been no large-scale prospective study on the association between SRH and functional disability in elderly people using LTCI with a long follow-up period (10 years or more).

Previous large population studies in Western countries have shown that elderly people with poor SRH are at a high risk for functional disabilities [20-23]. Poor SRH has also been shown to be strongly associated with mortality and functional decline in Japanese elderly residents [16-19]. The results of those studies indicate that SRH can be used for predicting future functional disabilities in Japanese.

Therefore, the aim of this study was to determine whether poor SRH increases the risk of functional disabilities in elderly Japanese people utilizing the certification of LTCI for 10 years.

\section{Methods}

The research plan was approved by the Ethics Committee of Iwate Medical University Institute Review Board \#1 (approval no. H13-33).

\section{Study population}

The original cohort of the Iwate-Kenpoku cohort (IwateKENCO) study, which is a population-based prospective study, consisted of residents Miyako, Ninohe, and Kuji districts in northern Iwate in Japan (Fig. 1). The IwateKENCO study began in 2002. The methodology has been described in detail in a previous report [24]. We performed the baseline survey from April to November in 2002 to 2004. Baseline examinations consisted of blood sampling, electrocardiography, anthropometrical examinations, blood pressure measurement, and a selfreported questionnaire with questions on self-rated health and medical history including the status of prescribed drugs. A total of 26,469 participants took part in multiphasic health checkups and agreed to complete the survey (acceptance rate, 84.5\%). We longitudinally conducted follow-up of those participants using the dates of LTIC, which the city government recorded until December 31, 2014 (median follow-up period: 10.5 years). Patients (a) aged 65 years and older, (b) with no certification for LTCI of the time of the baseline survey, (c) with no history of cardiovascular diseases (stroke, heart failure, and myocardial infarction) at the time of the baseline survey, (d) with complete follow-up, and (e) without lacking data for at least one variable necessary for the analysis were included in the analysis. Data were analyzed for a total of 10,960 participants (4333 men and 6627 women, mean age of 71.4 years) (Fig. 2).

\section{Self-rated health}

Self-rated health (SRH) was assessed by the single question: "How do you rate your health?" The five options included: "good," "rather good," "neither good nor poor," "rather poor," and "poor." This assessment was then reclassified into four categories: "good," "rather good," "neither good nor poor," and "poor".

\section{Endpoint measurement}

The endpoint of this study was incident functional disability, which is defined as receiving a new certification as an official recipient of the Japanese LTCI system [14]. It is nationally uniform criteria for LTCI, based on evaluation by the Certification Committee for long-term care need in municipalities. LTCI was used to validate physical and cognitive disabilities in elderly individuals in previous studies. One study showed that the levels of LTCI certification are closely associated with the ability to perform activities of daily living as assessed by the Barthel Index (Spearman's coefficient $=-0.86$ ) and with Mini-Mental State Examination scores (Spearman's coefficient $=-0.42$ ) [25]. Information on incident functional disability was obtained from the municipal public LTCI system database [26]. 


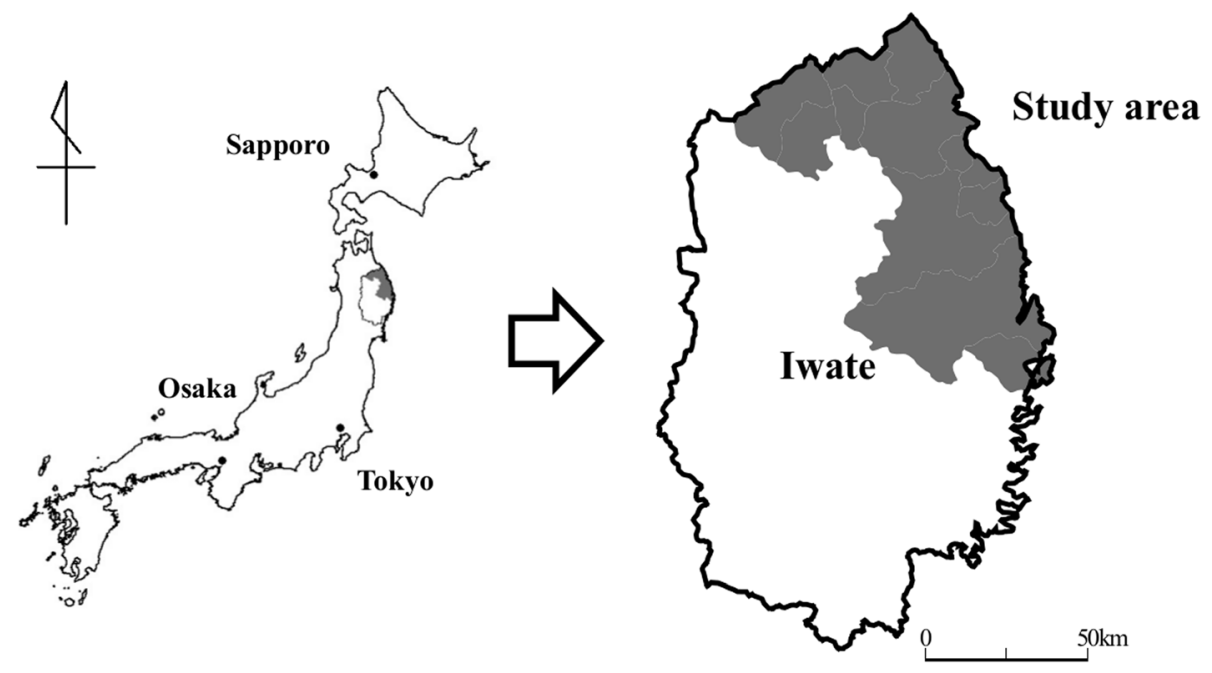

Fig. 1 Map of the present study. The figure shows a map of Japan and a map of Iwate Prefecture. The gray areas shown the region of the study in northern Iwate (software used to create the map: Mandara for Windows Version 9.10. http://ktgis.net/mandara/index.php)

For the process of certification in the LTCI system, an elderly person or his caregiver (family or professional) contacts the municipal government to apply for care needs [27]. Trained local government officials conduct a home visit to evaluate the patient's nursing care needs using a questionnaire regarding the patient's current physical status, mental status, and medical procedures. The results are entered into a computer to calculate the applicant's standardized scores for the seven dimensions of physical status and mental status, estimate the time required for the nine categories of care (grooming/bathing, eating, toileting, transferring, assistance with instrumental activities of daily living, behavioral problems, rehabilitation, and medical services), and assign a careneeds level based on the total estimated care minutes. The Nursing Care Needs Certification Board decides whether a LTCI certification will be provided or not after considering the results of the initial assessment

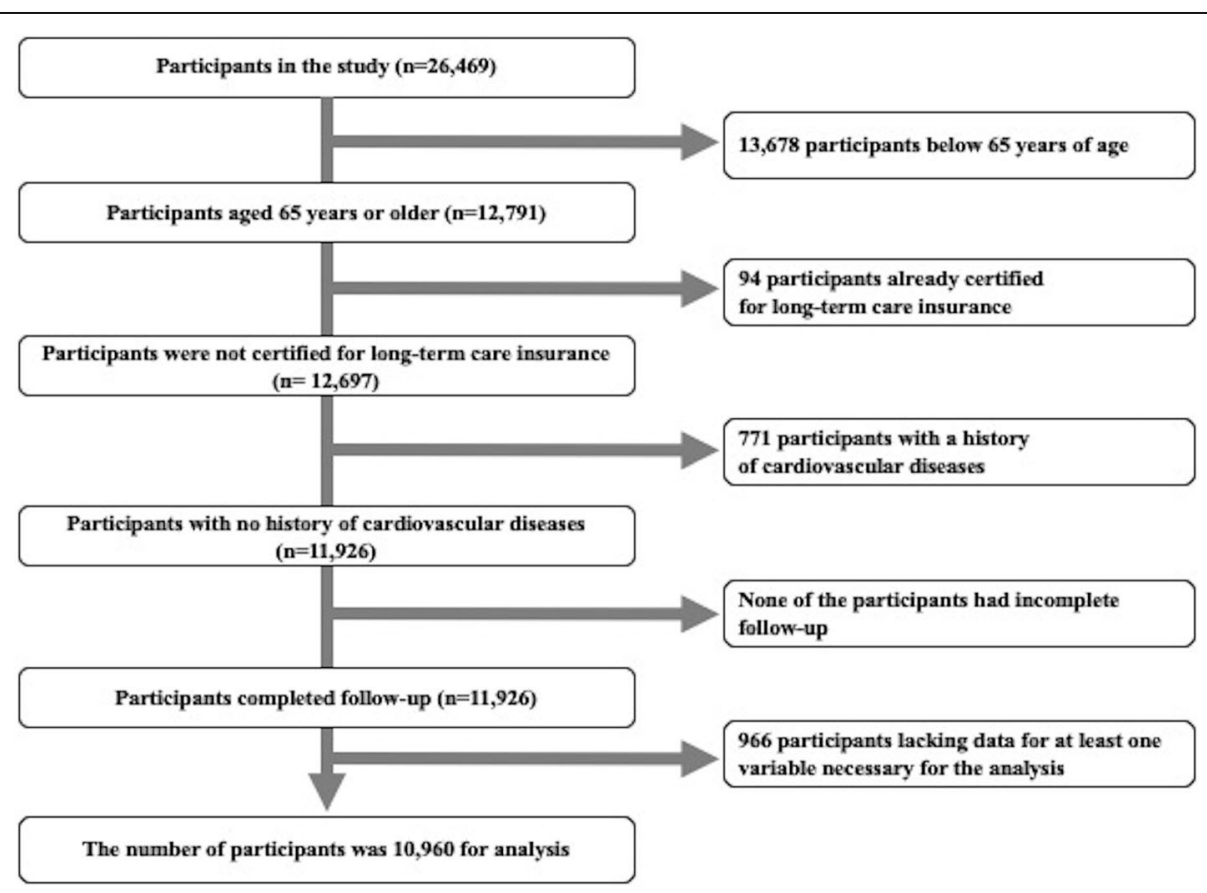

Fig. 2 Flow chart showing selection of participants in the study. The original cohort consisted of 26,469 participants in the baseline survey. After exclusion of participants according to the exclusion criteria, a total of 10,960 participants remained 
using the primary care physician's statement and notes written by the assessor during the home visit [28]. The levels of care consist of seven components: support levels 1 and 2 (i.e., individuals who require daily assistance) and care need levels 1 to 5 (i.e., individuals who are bedridden or in need of assistance such as assistance in eating and taking a bath). According to each level, applicants can receive the services covered by the fee for each service. Functional disability in any of the levels above LTCI items was defined as the endpoint [29].

\section{Baseline data and self-reported questionnaire}

Anthropometrical examinations including measurements of body weight $[\mathrm{kg}]$ and height $[\mathrm{cm}]$ were performed. Body mass index was calculated as body weight $[\mathrm{kg}] \mathrm{di}-$ vided by the square of height $[\mathrm{m}]$. Blood pressure, anthropometric data, results of blood tests (serum levels of total cholesterol (TC; $\mathrm{mg} / \mathrm{dl}$ ), high-density lipoprotein cholesterol (HDLC; $\mathrm{mg} / \mathrm{dl}$ ), non-high-density lipoprotein cholesterol (non-HDLC; mg/dl), hemoglobin (Hb; g/dl), and glycosylated hemoglobin (HbA1c; \%)), and estimated glomerular filtration rate (eGFR; $\left.\mathrm{mL} / \mathrm{min} / 1.73 \mathrm{~m}^{2}\right)$ were used for analysis [24, 29]. Participants answered a selfreported questionnaire that was prepared by the study committee. The questionnaire included questions about demographic characteristics (age and sex), socioeconomic status (job status, educational attainment, and marital status), health-related behaviors (smoking status, alcohol drinking status, exercise habits, and sleep duration), and past medical history (status of prescribed drugs for hypertension, diabetes mellitus, and dyslipidemia) [30]. Job status was dichotomized, having a job and non-employed or retired [30]. Education attainment was classified into 3 categories according to the duration of education: $\leq 9$ years, $10-12$ years and $\geq 13$ years. Marital status was also dichotomized: single (unmarried, divorce or bereavement) or married. Smoking status (current, past smoker or non-smoker) and alcohol drinking status (never drinker, past drinker, drinker $<1$ day per week, drinker 1-4 days per week, drinker $\geq 5$ days per week) were also ascertained by the self-reported questionnaire. In women, alcohol drinking status was classified into 2 groups: never drinker and drinker. Regular exercise habits were classified into three categories; $<1 \mathrm{~h}$ per week ( $<30 \mathrm{~min} 8$ times per month), $1-2 \mathrm{~h}$ per week ( 30 to $59 \mathrm{~min} 8$ times per month), and $\geq 2 \mathrm{~h}$ per week ( $\geq 60$ min 8 times per month) [30]. Sleep duration was categorized into 3 groups: $\leq 6 \mathrm{~h}$ per day, $7-8 \mathrm{~h}$ per a day, $\geq 9 \mathrm{~h}$ per day. Clinical cardiovascular (CV) risk factors in three diseases (hypertension, diabetes mellitus and dyslipidemia) were assessed [29]. Hypertension was defined as systolic blood pressure of $140 \mathrm{mmHg}$ or higher and/or diastolic blood pressure of $90 \mathrm{mmHg}$ or higher, and/or the use of medications for a hypertensive state. Diabetes mellitus was defined as a non-fasting glucose concentration of $200 \mathrm{mg} / \mathrm{dl}$ or higher, and/or fasting blood glucose level of $126 \mathrm{mg} / \mathrm{dl}$ or higher, and/or $\mathrm{HbAl}_{\mathrm{c}}$ value of $6.5 \%$ or higher, and/or the use of antidiabetic agents including insulin. Dyslipidemia was defined as serum TC level of $220 \mathrm{mg} / \mathrm{dl}$ or higher, serum HDLC level below $40 \mathrm{mg} / \mathrm{dl}$, and/or the use of medications for hyperlipidemia. Interim CV diseases were also assessed utilizing a composite of stroke, myocardial infarction, and heart failure from the baseline study to the followup survey [31].

\section{Statistical analyses}

All analyses were stratified by sex considering the difference in the baseline characteristics. Baseline factors are then compared among the four SRH groups. Continuous variables were expressed as means and standard deviation (SD), and categorical variables are expressed as proportions (\%). Analysis of covariance (continuous variables) or the chi squared test (categorical variables) was utilized to examine the differences between variables. A linear trend test was also performed between the SRH categories and each risk factor.

Hazard ratios (HRs) of risk factors for future development of functional disability and their 95\% confidential intervals (CIs) in the SRH groups (utilizing "good" SRH as the reference) were calculated using a multivariate Cox proportional hazard model after adjusting for covariates that were related to SRH in baseline characteristics of age, socioeconomic status, health-related behaviors, and objective indicators (i.e., BMI, systolic blood pressure, diastolic blood pressure, TC, non-HDLC, HDLC, $\mathrm{Hb}, \mathrm{HbA} 1 \mathrm{c}$, and eGFR) and were used as confounding factors. A sequence of two models was run. In Model 1, we included the independent variables of SRH. Model 2 was further adjusted for variables with a significant relation to SRH in baseline characteristics. To evaluate the influence of the incidence of cardiovascular disease, time-dependent Cox regression analyses (adjusted for interim CV diseases) were calculated in the HRs of the incident of functional disability. To determine the additive effect of objective indicators, we compared the HRs for the risk of functional disability among the SRH groups with and without adjustment for objective indicators.

To avoid the possibility of participants already having developed sub-clinical serious diseases at the baseline survey and being certified for LTCI in the near future, similar analyses were performed excluding participants who were LTCI-certified within 2 years after the initial survey. To examine whether poor SRH contributes to the development of a more serious disability, Cox regression analyses were performed by using another LTCI category, thus, using two re-classified LTCI categories (i.e., LTCI care need level 2 or more and others). LTCI 
care need level 2 was defined as the requirement of assistance in at least one basic ADL task [32]. P-values < 0.05 were considered statistically significant. The Statistical Package for Social Sciences (SPSS) software program version 24.0 (IBM, Chicago, IL, USA) was used to perform statistical analyses.

\section{Results}

The median follow-up period was 10.5 years (inter-quartile range, 10.1-12.4 years). During follow-up (112,490 person-years), 3377 participants were authorized as new recipients of LTCI for functional disability (1245 men and 2132 women, $3.3 \%$ per year). The median period to LTCI certification was 7.1 years (inter-quartile range, 4.3-9.3 years).

Baseline characteristics in the SRH groups are shown in Table 1. There was no significant difference in mean age among the SRH groups for both sexes. In men, SRH was worse in participants who were non-employed or retired, single, and never drinker and who had a low frequency of regular exercise, short sleep duration $(\leq 6 \mathrm{~h})$, long sleep duration ( $\geq 9 \mathrm{~h}$ ), hypertension, and diabetes mellitus. Worse SRH was also related to higher levels of HbA1c and non-HDLC, lower levels of DBP and Hb and lower eGFR. In women, SRH was worse in participants who were having a job, participants who never smoked, and participants who had a low frequency of regular exercise, hypertension, and diabetes mellitus. Furthermore, worse SRH was related to a high level of HbA1c, low levels of TC and non-HDLC, and low eGFR.

Table 2 shows the hazard ratios of functional disability among the SRH groups. The percentages of participants with functional disability increased with worsening of SRH (percentage in men: good SRH group, 25.9\%; rather good SRH group, 28.4\%; neither good nor poor SRH group, 29.6\%; poor SRH group, 42.2\%; percentages in women: good SRH group, 27.6\%; rather good $\mathrm{SRH}$ group, 30.7\%; neither good nor poor SRH group, 35.1\%; poor SRH group, 47.7\%). HRs of functional disability were found to be significantly higher in the neither good nor poor SRH group, and poor SRH group for men (HR [95\% CI] in men: neither good nor poor SRH group = $1.21[1.02,1.45]$, poor SRH group $=2.07[1.69,2.54])$ (Additional file 1). In women, HRs were significantly higher in three SRH groups (HR [95\% CI]: rather good $\mathrm{SRH}$ group $=1.15[1.03,1.28]$, neither good nor poor $\mathrm{SRH}$ group $=1.39[1.21,1.59]$, and poor $\mathrm{SRH}$ group $=$ $2.13[1.83,2.48]$ ). After adjustments for covariates were made, these differences disappeared in the neither good nor poor SRH group for men but remained statistically significant in the other groups in Model 2. There were significant linear trends between the SRH groups and functional disability for both sexes $(p<0.001)$. In men, HRs for functional disability were found to be significantly higher in participants who had a high HbA1c level, who were non-employed or retired, who had a single marital status, and who had a long sleep duration ( $\geq 9 \mathrm{~h}$ ), while HRs for functional disability were found to be significantly lower in participants with a high $\mathrm{Hb}$ level and high eGFR and who were drinkers 14 days per week. In women, HRs for functional disability were found to be significantly higher in participants who had a high level of HbA1c, who were non-employed or retired, who had a single marital status and who had a low frequency of physical exercise ( $<1 \mathrm{~h}$ per week), while HRs for functional disability were found to be significantly lower in participants with a high eGFR. Figure 3 showes the cumulative survival curve of functional disability-free rates in the SRH groups. The differences in cumulative probability of functional disability-free rates among the SRH groups were significant $(p<0.001)$. Utilizing time-dependent Cox regression analysis with incorporation of the interim $\mathrm{CV}$ diseases, the $\mathrm{HR}$ for functional disability showed significant increases for men in the poor SRH group and for women in three SRH groups (Additional file 2).

The HRs for the risk of functional disability were further compared in the SRH groups with and without adjustments for objective indicators (Additional file 3). The HRs for the risk of functional disability remained significantly high in the poor SRH group in both models. After excluding sub-clinical cases, a significant association was found only in the poor SRH group for men, but significant associations remained in all three SRH groups for women (Table 3). In analysis of severe functional disability, the HRs for men were attenuated in all three SRH groups and a significant association was found for the poor SRH group. The HRs for functional disability for women were attenuated, but significant associations remained in the worst group. The linear trends show significant associations for both sexes in these analyses.

\section{Discussion}

In the present study, SRH in the baseline survey was found a strong predictor of functional disability by utilizing certification of LTCI in a community of Japanese elderly dwellers. A linear relationship was found between the incidence of functional disability and SRH. In addition, poorer SRH group was significantly higher risk for functional disability in analysis excluding participants who were functionally disabled within the initial 2 years of the survey. Furthermore, the association between SRH and functional disability remained significant in analysis of the endpoint for severe cases of functional disability.

Most of the previous studies on the relationship between poor SRH and functional disability were conducted in Western countries [20-23, 33]. The results of our study are in line with the results of studies in 
Table 1 Characteristics of participants in the self-rated health groups $(n=10,960)$

\begin{tabular}{|c|c|c|c|c|c|c|}
\hline Men $(n=4333)$ & & $\begin{array}{l}\text { Good }(n= \\
1412)\end{array}$ & $\begin{array}{l}\text { Rather good }(n= \\
\text { 1990) }\end{array}$ & $\begin{array}{l}\text { Neither good nor poor } \\
(n=635)\end{array}$ & $\begin{array}{l}\text { Poor }(n= \\
296)\end{array}$ & $\begin{array}{l}P \text { for } \\
\text { trend }\end{array}$ \\
\hline Age & Age (yr) & $71.7(5.0)$ & $71.7(4.8)$ & $71.6(4.8)$ & $72.6(5.0)$ & 0.307 \\
\hline $\begin{array}{l}\text { Anthropometrical } \\
\text { examinations }\end{array}$ & BMI $\left(\mathrm{kg} / \mathrm{m}^{2}\right)$ & $23.6(2.8)$ & $23.7(2.9)$ & $23.6(3.1)$ & $23.6(3.2)$ & 0.901 \\
\hline \multirow[t]{2}{*}{ Blood pressure } & $\mathrm{SBP}(\mathrm{mmHg})$ & $134.8(20.4)$ & $133.3(19.0)$ & $134.3(20.9)$ & $132.0(19.2)$ & 0.062 \\
\hline & $\mathrm{DBP}(\mathrm{mmHg})$ & $78.3(10.5)$ & $77.7(10.4)$ & $78.1(11.0)$ & $76.4(10.2)$ & 0.022 \\
\hline \multirow[t]{6}{*}{ Biochemical data } & $\mathrm{TC}(\mathrm{mg} / \mathrm{dl})$ & $189.1(31.0)$ & $189.7(30.9)$ & $185.6(31.9)$ & $188.0(32.4)$ & 0.096 \\
\hline & HDLC (mg/dl) & $56.2(15.4)$ & $56.0(15.2)$ & $56.3(14.8)$ & $54.3(15.1)$ & 0.197 \\
\hline & Non-HDLC (mg/dl) & $132.9(31.0)$ & $133.7(30.7)$ & $129.4(31.8)$ & $133.7(31.7)$ & 0.022 \\
\hline & $\mathrm{Hb}(\mathrm{g} / \mathrm{dl})$ & $14.5(1.3)$ & $14.4(1.3)$ & $14.4(1.3)$ & $14.2(1.5)$ & 0.014 \\
\hline & HbA1c (\%) & $5.5(0.7)$ & $5.6(0.8)$ & $5.6(0.8)$ & $5.7(0.9)$ & $<0.001$ \\
\hline & $\begin{array}{l}\text { eGFR }(\mathrm{mL} / \mathrm{min} / \\
\left.1.73 \mathrm{~m}^{2}\right)\end{array}$ & $71.3(8.7)$ & $70.5(9.1)$ & $70.3(9.9)$ & $69.0(11.4)$ & $<0.001$ \\
\hline Job status & $\begin{array}{l}\text { Non-employed or } \\
\text { retired }\end{array}$ & 57.5 & 61.7 & 66.9 & 67.9 & $<0.001$ \\
\hline \multirow[t]{3}{*}{ Educational attainment } & $\leq 9 \mathrm{yrs}$ & 72.7 & 68.8 & 68.7 & 68.2 & 0.097 \\
\hline & $10-12$ yrs & 19.3 & 22.8 & 22.8 & 23.6 & \\
\hline & $\geq 13$ yrs & 8.1 & 8.4 & 8.5 & 8.1 & \\
\hline Marital status & Single & 8.6 & 9.9 & 11.7 & 12.8 & 0.005 \\
\hline \multirow[t]{3}{*}{ Smoking status } & Never smoker & 45.8 & 40.5 & 39.7 & 36.1 & 0.414 \\
\hline & Past smoker & 29.2 & 36.2 & 36.1 & 44.3 & \\
\hline & Current smoker & 25.0 & 23.3 & 24.3 & 19.6 & \\
\hline \multirow[t]{5}{*}{ Drinking status } & Never drinker & 28.3 & 26.1 & 22.7 & 32.4 & $<0.001$ \\
\hline & Past drinker & 7.6 & 10.1 & 14.6 & 21.3 & \\
\hline & $\begin{array}{l}\text { Drinker }<1 \text { day per } \\
\text { week }\end{array}$ & 5.9 & 7.5 & 8.0 & 7.1 & \\
\hline & $\begin{array}{l}\text { Drinker 1-4 days per } \\
\text { week }\end{array}$ & 16.3 & 14.5 & 13.1 & 11.8 & \\
\hline & $\begin{array}{l}\text { Drinker } \geq 5 \text { days per } \\
\text { week }\end{array}$ & 41.9 & 41.8 & 41.6 & 27.4 & \\
\hline \multirow[t]{3}{*}{ Exercise habits } & $<1 \mathrm{~h}$ per week & 70.2 & 69.9 & 73.4 & 79.7 & 0.006 \\
\hline & $1-2 \mathrm{~h}$ per week & 8.1 & 7.2 & 6.1 & 5.4 & \\
\hline & $>2 \mathrm{~h}$ per week & 21.7 & 22.9 & 20.5 & 14.9 & \\
\hline \multirow[t]{3}{*}{ Sleep duration } & $\leq 6 \mathrm{~h}$ & 8.4 & 8.8 & 7.7 & 9.5 & 0.049 \\
\hline & $7-8 h$ & 54.8 & 52.6 & 49.4 & 48.6 & \\
\hline & $\geq 9 \mathrm{~h}$ & 36.8 & 38.5 & 42.8 & 41.9 & \\
\hline Hypertension & Hypertension & 51.9 & 55.7 & 58.7 & 57.1 & 0.005 \\
\hline Diabetes mellitus & Diabetes mellitus & 8.1 & 11.9 & 13.5 & 17.6 & $<0.001$ \\
\hline Dyslipidemia & Dyslipidemia & 27.3 & 29.4 & 24.6 & 35.8 & 0.164 \\
\hline Interim CV diseases & Interim CV diseases & 12.7 & 11.3 & 11.5 & 12.2 & 0.510 \\
\hline Women $(n=6627)$ & & $\begin{array}{l}\text { Good }(n= \\
1624)\end{array}$ & $\begin{array}{l}\text { Rather good }(n= \\
\text { 3292) }\end{array}$ & $\begin{array}{l}\text { Neither good nor poor } \\
(n=1143)\end{array}$ & $\begin{array}{l}\text { Poor }(n= \\
568)\end{array}$ & $\begin{array}{l}P \text { for } \\
\text { trend }\end{array}$ \\
\hline Age & Age (yr) & $71.1(4.6)$ & $71.1(4.5)$ & $71.3(70.9)$ & $71.4(4.5)$ & 0.638 \\
\hline $\begin{array}{l}\text { Anthropometrical } \\
\text { examinations }\end{array}$ & BMI $\left(\mathrm{kg} / \mathrm{m}^{2}\right)$ & $24.3(3.3)$ & $24.2(3.4)$ & $24.5(3.6)$ & $24.5(3.8)$ & 0.084 \\
\hline \multirow[t]{2}{*}{ Blood pressure } & $\mathrm{SBP}(\mathrm{mmHg})$ & $130.3(19.4)$ & $131.7(19.7)$ & $132.2(20.2)$ & $129.9(18.7)$ & 0.450 \\
\hline & DBP $(\mathrm{mmHg})$ & $74.6(10.4)$ & $75.2(10.4)$ & $75.2(10.6)$ & $74.1(10.4)$ & 0.053 \\
\hline
\end{tabular}


Table 1 Characteristics of participants in the self-rated health groups $(n=10,960)$ (Continued)

\begin{tabular}{|c|c|c|c|c|c|c|}
\hline \multirow[t]{6}{*}{ Biochemical data } & $\mathrm{TC}(\mathrm{mg} / \mathrm{dl})$ & $209.4(31.2)$ & $206.9(30.4)$ & $206.5(30.8)$ & $205.7(30.9)$ & 0.004 \\
\hline & HDLC (mg/dl) & $59.8(14.2)$ & $59.8(14.6)$ & $59.7(14.1)$ & $59.6(14.1)$ & 0.786 \\
\hline & Non-HDLC (mg/dl) & $149.7(31.3)$ & $147.1(29.8)$ & $146.8(30.5)$ & $146.1(30.5)$ & 0.015 \\
\hline & $\mathrm{Hb}(\mathrm{g} / \mathrm{dl})$ & $13.0(1.1)$ & $13.0(1.1)$ & $12.9(1.1)$ & $13.0(1.1)$ & 0.249 \\
\hline & HbA1c (\%) & $5.6(0.6)$ & $5.6(0.6)$ & $5.6(0.7)$ & $5.7(0.8)$ & $<0.001$ \\
\hline & $\begin{array}{l}\text { eGFR }(\mathrm{mL} / \mathrm{min} / \\
\left.1.73 \mathrm{~m}^{2}\right)\end{array}$ & $71.9(8.5)$ & $71.9(8.1)$ & $71.4(9.0)$ & $70.4(9.7)$ & 0.001 \\
\hline Job status & $\begin{array}{l}\text { Non-employed or } \\
\text { retired }\end{array}$ & 28.6 & 27.0 & 22.0 & 19.2 & $<0.001$ \\
\hline \multirow[t]{3}{*}{ Educational attainment } & $\leq 9 \mathrm{yrs}$ & 79.1 & 77.7 & 79.5 & 82.0 & 0.139 \\
\hline & $10-12$ yrs & 17.5 & 17.5 & 17.3 & 15.3 & \\
\hline & $\geq 13$ yrs & 3.3 & 4.7 & 3.1 & 2.6 & \\
\hline Marital status & Single & 36.5 & 36.1 & 38.6 & 40.5 & 0.054 \\
\hline \multirow[t]{3}{*}{ Smoking status } & Never smoker & 98.3 & 98.9 & 99.0 & 99.6 & 0.008 \\
\hline & Past smoker & 0.7 & 0.4 & 0.4 & 0.4 & \\
\hline & Current smoker & 0.9 & 0.7 & 0.5 & 0.0 & \\
\hline \multirow[t]{5}{*}{ Drinking status } & Never drinker & 88.2 & 89.5 & 89.1 & 88.2 & 0.537 \\
\hline & Past drinker & 0.5 & 0.6 & 1.1 & 2.1 & \\
\hline & $\begin{array}{l}\text { Drinker }<1 \text { day per } \\
\text { week }\end{array}$ & 4.2 & 3.5 & 3.5 & 2.5 & \\
\hline & $\begin{array}{l}\text { Drinker } 1-4 \text { days per } \\
\text { week }\end{array}$ & 4.7 & 4.4 & 4.5 & 4.8 & \\
\hline & $\begin{array}{l}\text { Drinker } \geq 5 \text { days per } \\
\text { week }\end{array}$ & 2.3 & 2.0 & 1.8 & 2.5 & \\
\hline \multirow[t]{3}{*}{ Exercise habits } & $<1 \mathrm{~h}$ per week & 78.4 & 81.8 & 83.0 & 85.2 & $<0.001$ \\
\hline & 1-2 h per week & 8.0 & 7.4 & 7.8 & 8.1 & \\
\hline & $>2 \mathrm{~h}$ per week & 13.6 & 10.7 & 9.2 & 6.7 & \\
\hline \multirow[t]{3}{*}{ Sleep duration } & $\leq 6 \mathrm{~h}$ & 12.1 & 12.5 & 13.6 & 17.6 & 0.552 \\
\hline & $7-8 h$ & 61.9 & 61.1 & 56.4 & 50.9 & \\
\hline & $\geq 9 \mathrm{~h}$ & 25.9 & 26.5 & 29.9 & 31.5 & \\
\hline Hypertension & Hypertension & 48.3 & 55.8 & 57.8 & 60.6 & $<0.001$ \\
\hline Diabetes mellitus & Diabetes mellitus & 6.0 & 6.6 & 8.7 & 11.3 & $<0.001$ \\
\hline Dyslipidemia & Dyslipidemia & 43.2 & 42.5 & 42.3 & 46.3 & 0.449 \\
\hline Interim CV diseases & Interim CV diseases & 6.5 & 7.4 & 7.5 & 6.0 & 0.888 \\
\hline
\end{tabular}

Abbreviations: $B M I$ body mass index, $C V$ diseases cardiovascular disease, $D B P$ diastolic blood pressure, eGFR estimated glomerular filtration rate, $H b$ hemoglobin, $H b A 1 c$ glycosylated hemoglobin, HDLC high-density lipoprotein cholesterol, Non-HDLC non-high-density lipoprotein cholesterol, SBP systolic blood pressure, TC total cholesterol

Continuous variables were expressed as the mean (standard deviation) and Categorical variables were expressed as the proportion

The difference between the variables and the trend were tested by using an analysis of covariance test (continuous variables) or the chi-squared test (categorical variables)

Western countries. Several studies have shown a relationship between SRH and the development of functional disability in Japan. Haga et al. demonstrated an association between SRH and ADL that were rated on the basis of five items (e.g., walking and dressing) [34]. Hirosaki et al. revealed an association between SRH and functional ability that was evaluated on the basis of basic ADL using seven items in community-dwelling Japanese elderly adults [17]. Compared with our study, these studies had a smaller sample size (124 in Haga's study, and
654 in Hirosaki's study). Additionally, the endpoints in those studies (ADL and basic ADL) were different from the endpoint in this study although the focus in both of those studies had similarities with the focus of the current study in terms of elucidating the association of SRH with functional disability. In the present study, functional disability as the endpoint was defined according to the levels of the abovementioned LTCI items (from support levels 1 and 2 and care need levels 1 to 5 ). People in support level 1 were defined as "those with 
Table 2 Hazard ratios for functional disability among the self-rated health groups utilizing a multivariate Cox regression analysis

\begin{tabular}{|c|c|c|c|c|c|c|c|c|}
\hline & \multicolumn{7}{|c|}{ Self-rated health } & \multirow{2}{*}{$\begin{array}{l}\boldsymbol{P} \text { for } \\
\text { trend }\end{array}$} \\
\hline & Good & Rather good & & $\begin{array}{l}\text { Neither go } \\
\text { poor }\end{array}$ & od nor & Poor & & \\
\hline \multicolumn{9}{|l|}{ Men $(n=4333)$} \\
\hline Number of participants & 1412 & 1990 & & 635 & & 296 & & \\
\hline Number of cases (person-years/1000 person-years) & $366(2.55)$ & $566(3.87)$ & & $188(1.21)$ & & $125(0.71)$ & & \\
\hline $\mathrm{HR}, 95 \% \mathrm{Cl}$ & 1 (reference) & 1.04 & $0.92,1.19$ & 1.06 & $0.89,1.27$ & 1.74 & $1.42,2.14$ & $<0.001$ \\
\hline \multicolumn{9}{|l|}{ Women $(n=6627)$} \\
\hline Number of participants & 1624 & 3292 & & 1143 & & 568 & & \\
\hline Number of cases (person-years/1000 person-years) & $449(3.14)$ & $1011(6.92)$ & & $401(2.58)$ & & $271(1.55)$ & & \\
\hline $\mathrm{HR}, 95 \% \mathrm{Cl}$ & 1 (reference) & 1.12 & $1.00,1.25$ & 1.29 & $1.13,1.48$ & 1.92 & $1.65,2.24$ & $<0.001$ \\
\hline
\end{tabular}

Abbreviations: $\mathrm{Cl}$ confidence interval, $H R$ hazard ratios

Cox regression analysis adjusted for the variables below

Men: diastolic blood pressure, non-high-density lipoprotein cholesterol, hemoglobin, glycosylated hemoglobin, estimated glomerular filtration rate, job status, marital status, alcohol drinking status, regular exercise habits, and sleep duration

Women: total cholesterol, non-high-density lipoprotein cholesterol, glycosylated hemoglobin, estimated glomerular filtration rate, job status, marital status, and regular exercise habits

limited ability to perform instrumental activities of daily living but remaining independent in basic activities of daily living." [25]. This endpoint is compatible with the endpoint of Lee's study and Hirai's study in which functional disability was defined as disability including IADL limitations. Lee investigated the extent to which elderly people's self-assessments of general health including SRH predicted functional decline in the US Longitudinal Study of Aging (LSOA) [21]. The odds ratios of functional decline were significantly higher in those who responded good, fair, or poor for SRH than in those who responded excellent (odds ratios [95\% CI] : good SRH group $=1.43[1.16,1.76]$ and fair/poor SRH group $=1.56$
$[1.20,2.03])$. Although analysis with stratification by sex was not performed in Lee's study, the classification of SRH (which was divided into four categories) was compatible with that in our study, and the magnitude of risk for functional disability was similar to that of our results. Hirai et al. examined risk factors for certification of LTCI in community dwelling elderly [19]. SRH was significantly related to increased risk of onset of LTCI in persons in support level 1 or more (HR [95\% CI]: men in the poor SRH group $=2.79[2.25,3.47]$; women, in the poor SRH group $=2.28[1.91,2.73])$. Although the endpoint in Hirai's study was exactly the same as that in our study, the classification of SRH (which was divided into
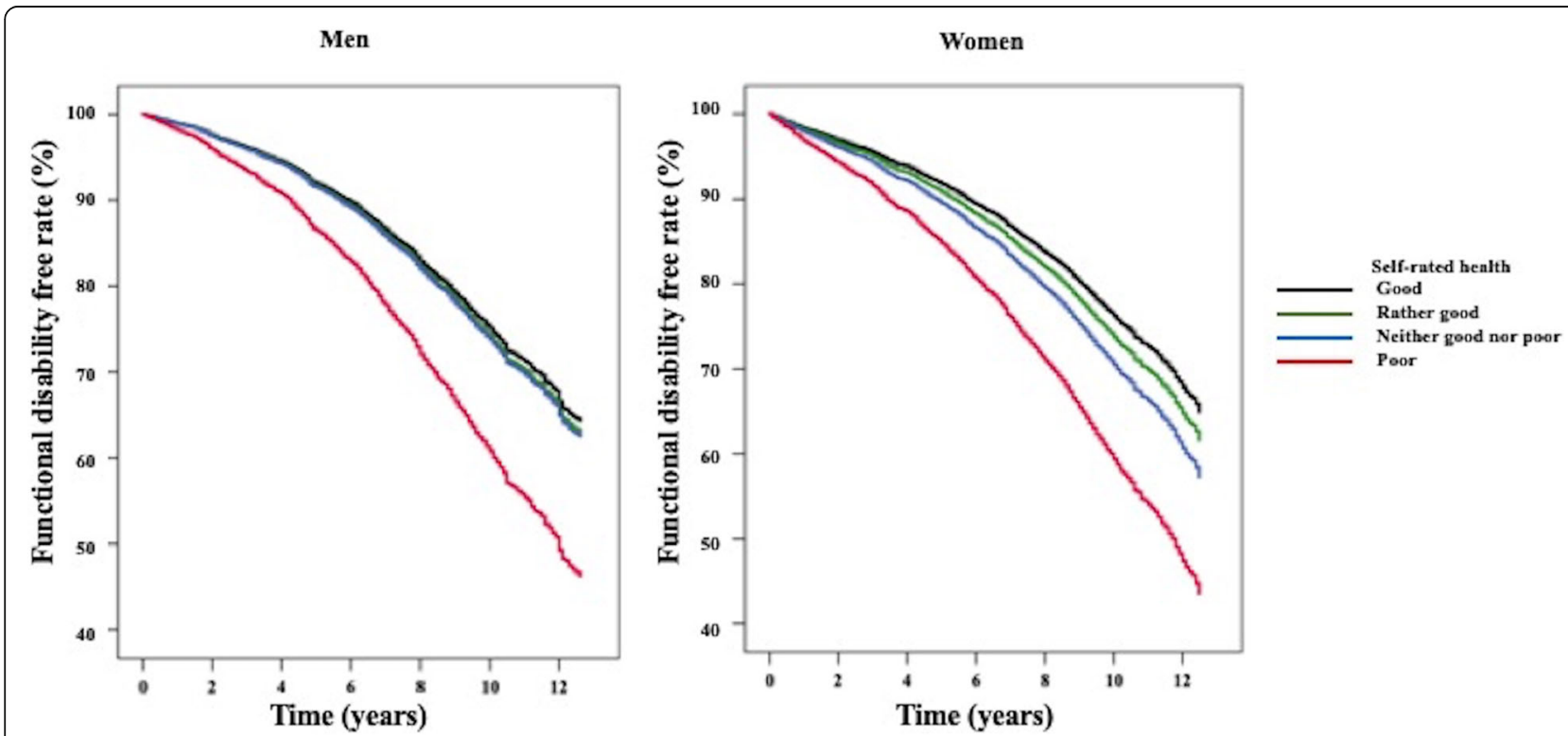

Fig. 3 The cumulative survival curve of functional disability-free rates in the self-rated health groups 
Table 3 Hazard ratios for functional disability among the self-rated health groups excluding participants with sub-clinical and severe cases

\begin{tabular}{|c|c|c|c|c|c|c|c|c|}
\hline & \multicolumn{7}{|c|}{ Self-rated health } & \multirow{2}{*}{$\begin{array}{l}P \text { for } \\
\text { trend }\end{array}$} \\
\hline & Good & \multicolumn{2}{|c|}{ Rather good } & \multicolumn{2}{|c|}{$\begin{array}{l}\text { Neither good nor } \\
\text { poor }\end{array}$} & \multicolumn{2}{|l|}{ Poor } & \\
\hline \multicolumn{9}{|c|}{ Functional disability excluded participants who were sub-clinical cases } \\
\hline \multicolumn{9}{|l|}{ Men $(n=4126)$} \\
\hline Number of participants & 1356 & 1899 & & 605 & & 266 & & \\
\hline $\begin{array}{l}\text { Number of the cases (person-years/1000 person- } \\
\text { years) }\end{array}$ & $342(2.52)$ & $\begin{array}{l}517 \\
(3.82)\end{array}$ & & $\begin{array}{l}172 \\
(1.19)\end{array}$ & & $\begin{array}{l}102 \\
(1.50)\end{array}$ & & \\
\hline $\mathrm{HR}, 95 \% \mathrm{Cl}$ & $\begin{array}{l}1 \\
\text { (reference) }\end{array}$ & 1.02 & $\begin{array}{l}0.89 \\
1.17\end{array}$ & 1.05 & $\begin{array}{l}0.87 \\
1.27\end{array}$ & 1.58 & $\begin{array}{l}1.26 \\
1.98\end{array}$ & 0.001 \\
\hline \multicolumn{9}{|l|}{ Women $(n=6323)$} \\
\hline Number of participants & 1569 & 3166 & & 1081 & & 507 & & \\
\hline Number of cases (person-years/1000 person-years) & $410(3.10)$ & $\begin{array}{l}918 \\
(6.83)\end{array}$ & & $\begin{array}{l}349 \\
(2.52)\end{array}$ & & $\begin{array}{l}213 \\
(1.50)\end{array}$ & & \\
\hline $\mathrm{HR}, 95 \% \mathrm{Cl}$ & $\begin{array}{l}1 \\
\text { (reference) }\end{array}$ & 1.12 & $\begin{array}{l}1.00 \\
1.26\end{array}$ & 1.25 & $\begin{array}{l}1.08, \\
1.44\end{array}$ & 1.71 & $\begin{array}{l}1.45 \\
2.02\end{array}$ & $<0.001$ \\
\hline \multicolumn{9}{|l|}{ Functional disability in severe cases } \\
\hline \multicolumn{9}{|l|}{ Men $(n=4333)$} \\
\hline Number of participants & 1412 & 1990 & & 635 & & 296 & & \\
\hline Number of cases (person-years/1000 person-years) & $258(1.82)$ & $\begin{array}{l}401 \\
(2.72)\end{array}$ & & $\begin{array}{l}129 \\
(0.85)\end{array}$ & & $84(0.48)$ & & \\
\hline $\mathrm{HR}, 95 \% \mathrm{Cl}$ & $\begin{array}{l}1 \\
\text { (reference) }\end{array}$ & 1.03 & $\begin{array}{l}0.85 \\
1.26\end{array}$ & 1.12 & $\begin{array}{l}0.86 \\
1.46\end{array}$ & 1.71 & $\begin{array}{l}1.26 \\
2.33\end{array}$ & 0.004 \\
\hline \multicolumn{9}{|l|}{ Women $(n=6627)$} \\
\hline Number of participants & 1624 & 3292 & & 1143 & & 568 & & \\
\hline Number of cases (person-years/1000 person-years) & $254(1.84)$ & $\begin{array}{l}510 \\
(3.57)\end{array}$ & & $\begin{array}{l}211 \\
(1.37)\end{array}$ & & $\begin{array}{l}139 \\
(0.83)\end{array}$ & & \\
\hline $\mathrm{HR}, 95 \% \mathrm{Cl}$ & $\begin{array}{l}1 \\
\text { (reference) }\end{array}$ & 0.98 & $\begin{array}{l}0.85 \\
1.14\end{array}$ & 1.17 & $\begin{array}{l}0.97 \\
1.40\end{array}$ & 1.62 & $\begin{array}{l}1.31 \\
1.99\end{array}$ & $<0.001$ \\
\hline
\end{tabular}

Abbreviations: $\mathrm{Cl}$ confidence interval, $H R$ hazard ratios

Cox regression analysis adjusted for the variables below

Men: diastolic blood pressure, non-high-density lipoprotein cholesterol, hemoglobin, glycosylated hemoglobin, estimated glomerular filtration rate, job status, marital status, alcohol drinking status, regular exercise habits, and sleep duration

Women: total cholesterol, non-high-density lipoprotein cholesterol, glycosylated hemoglobin, estimated glomerular filtration rate, job status, marital status, and regular exercise habits

two categories [good vs. poor]) was not compatible with that in our study. Furthermore, the HRs of risk for functional disability were higher in Hirai's study than in our study possibly due to dichotomizing rather poor and poor as a poor SRH group. Our results suggest that poor SRH could be a predictor of functional disability even with some IADL limitations. Since SRH has also been recommended as a tool for disease risk screening [1], our results will be important role for estimation of the risk of functional disability in a general population.

The strength of this study was that we showed an association between SRH and functional disability in a large-scale prospective study in elderly community dwellers in East Asia over 10 years. Additional analyses such as analysis with exclusion of early cases and severe cases in endpoints improved the validity of our study. In addition, we showed an between SRH and functional disability even when adjustments were made for association objective indicators.

The results obtained by using the two models indicated that the association between SRH and functional disability was explained to some extent by confounding factors such as clinical indicators, social factors, and lifestyle, but there might have been residual confounders such as household income and the existence of mental disorders that were not incorporated in the models. Unfavorable social risk factors (non-employed or retired and single marital status) and unhealthy objective indicators (low $\mathrm{Hb}$ level, low eGFR, and high HbA1c level) contributed to the higher risk of functional disability. These results are consistent with the results of previous studies [35-37]. People with unfavorable social status 
and unhealthy status might conceive their health as being poor, which consequently lead to be functional disability.

$\mathrm{CV}$ diseases are well-known risks for future functional disability [38-41]. The main reasons for receiving LTCI were cerebrovascular disease (stroke) (21.5\%) followed by dementia (15.3\%) [42]. Several studies have demonstrated that poor SRH is a consistent predictor of the incidence of several type of $\mathrm{CV}$ diseases such as stroke, coronary artery disease, and heart failure [4, 43, 44]. Based on these facts, we initially hypothesized that poor SRH related to functional disability was mediated by physical dysfunctions caused by CV diseases. However, HRs of the incident risk for functional disability did not change in time-dependent Cox regression analyses adjusted for interim CV diseases. Another possibility for the higher incidence of functional disability in people with poor SRH is the influence of dementia. Poor SRH was shown to be a risk for incident dementia [8], and decline in cognitive function was shown to be associated with LTCI after an 18-month observation using a cognitive performance scale [45]. Lin et al. reported that people with dementia who lived alone had a higher risk of care needs than did those without dementia [46]. Although we were not able to evaluate the causes of functional disability due to a lack of information about cognitive dysfunction, we speculate that dementia relates to functional disability in elderly adults with poor SRH.

Previous studies have shown that poor SRH is associated with objective indicators such as serum cholesterol and HbA1c levels $[47,48]$, and studies have shown that cardiovascular risk factors are associated with functional disability $[49,50]$. In most previous studies, only subjective indicators such as self-reported information or interview-based information was examined even though these subjective items cannot be avoided by a recall bias [17-19]. Jylhä et al. mentioned the importance of investigating SRH adjusted for biological or clinical variables [51]. Therefore, adjustment for these clinical indicators gives light to new findings in the relationship between SRH and functional disability. In the analysis in the present study, after adjusting for clinically verified health indicators (such as results of anthropometrical examination and blood tests), poor SRH remained independently associated with functional disability. Even though there may still be residual confounding, e.g., inflammatory biomarkers, that does not allow for full adjustment, we could show a significant association between SRH and functional disability independent of objective indicators.

Though the mechanisms underlying the predictive ability of SRH for functional disability were not revealed in this study, there are some possible explanations of this pathway from poor SRH to functional disability. It is believed that the incidence of functional disability in the present study was affected by physical impairment and also cognitive dysfunction [42]. In pathophysiology, there is an association between SRH and subcortical dysfunction, which are often linked to vascular risk factors [52]. Gray matter atrophy and cortical thinning, as a consequence of microvascular diseases, cause neuronal damage [53]. Neuronal damage might lead to cognitive dysfunction by expressing social vulnerability [52]. In addition, recent studies have shown that SRH is related to several inflammatory biomarkers including $\mathrm{C}$-reactive protein and cytokines [30, 54]. High IL-6 plasma levels are associated with functional impairment in elderly individuals with vascular dementia [55]. A previous study showed that albuminuria predicted future functional disability [29]. Given these findings, poor SRH might be an alternative index of functional disability with physical impairment and cognitive dysfunction caused by asymptomatic brain infarction or endothelial dysfunction.

\section{Limitations}

The present study had several limitations. First, variables concerning psychological factors (e.g., depression) or subjective symptoms (which are associated with poor SRH and functional disability) were not included in the study [17]. The association of poor SRH with functional disability remained significant in a sub-group analysis (Additional file 4). Second, cancer incidence could not be included in the analysis due to a lack of information. Third, the actual causes of functional disability (e.g., physical and cognitive dysfunctions) were not identified. Notably, we could not incorporate the influence of dementia, which is one of the main reasons for receiving LTCI. Fourth, there might be reverse causation between poor SRH and functional disability. Because a significant association between SRH groups and participants with functional disability was found in the analysis excluding individuals with LTCI certification within 2 years from the initial survey, the influence of reverse causation might be small. Fifth, the generalizability of the results is not clear since the prevalence of LTCI was lower in the current study than in representative national surveys $[56,57]$. Furthermore, since participants in this study received a health check-up, they might be healthier or have more awareness of health than non-participants. Although this assumption might be underestimated, it is believed that the relationship between SRH and functional disability shows a true association. Finally, the distribution of SRH was not similar to national representative data. We showed the distribution of SRH between the data of the Comprehensive Survey of Living Conditions in Japan in 2004 and the data of our study [58] (Additional file 5). In the data of the Comprehensive Survey of Living Conditions, neither good nor 
poor SRH group had a higher percentage of participants. In the present study, rather good SRH group had a higher percentage of participants for both sexes. Individuals in the present study tended to provide more favorable answers than did participants in the national survey. Our participants might be healthier citizens. Present results might not be generalizable to a broader sample of elderly individuals.

\section{Conclusion}

Poorer SRH was significantly related to higher hazard ratios for future functional disability in both sexes among the Japanese community-dwelling elderly participants. Although it is difficult to accurately predict future functional disability using a single question, SRH might be useful for predicting later functional disability in elderly people as a simple, low-cost questionnaire, thus allowing for identification of high-risk individuals for future functional disability at an early stage.

\section{Supplementary information}

Supplementary information accompanies this paper at https://doi.org/10. 1186/s12877-020-01743-0.

Additional file 1. Hazard ratios for functional disability in the self-rated health groups using multivariate Cox regression analysis with exclusion of variables not related to self-rated health in the baseline comparison.

Additional file 2. Time-dependent Cox regression analysis to predict functional disability in the self-rated health groups.

Additional file $\mathbf{3}$ Comparison of hazard ratios for the risk of functional disability in the self-rated health groups with and without objective indicators (adjusted model).

Additional file 4. Hazard ratios for future functional disability in the selfrated health groups stratified by baseline data utilizing multivariate Cox regression analysis.

Additional file 5. Comparison of the distribution of self-rated health between Comprehensive Survey of Living Conditions in Japan in 2004 and the present study.

\section{Abbreviations}

ADL: Activities of daily living; BMl: Body mass index; Cl: Confidence interval; CV diseases: Cardiovascular diseases; DBP: Diastolic blood pressure; eGFR: Estimated glomerular filtration rate; Hb: Hemoglobin; HbA1c: Glycosylated hemoglobin; HDLC: High-density lipoprotein cholesterol; HR: Hazard ratio; LTCI: Long-term care insurance; non-HDLC: Non-highdensity lipoprotein cholesterol; SBP: Systolic blood pressure; SD: Standard deviation; SRH: Self-rated health; TC: Total cholesterol

\section{Acknowledgments \\ The authors would like to thank the participants of this study, the staff of Iwate Health Service Association and the staff in all municipalities (Iwate Prefecture, Ninohe City, Ichinohe Town, Karumai Town, Kunohe Village, Yamada Town, Miyako City, Iwaizumi Town, Tanohata Village, Kuji City, Fudai Village, Noda Village and Hirono Town). This project was conducted with the support of the Takemi Program in International Health at the Harvard T.H. Chan School of Public Health. We thank Prof. Ichiro Kawachi for contributing to the supervision of the lead author during his fellowship.}

\section{Authors' contributions}

Each author's Contribution is as following, ST, YY and KT conceptualized and designed the study, drafted the initial manuscript, and reviewed and revised the manuscript. MO, TK and KI helped supervise the statistical analysis, interpretation of the results, and prepare the discussion section of the text. $\mathrm{KS}$ and $\mathrm{AO}$ designed the study, directed its implementation and revised the manuscript. YI, SO, FT, RS, MT, ET, MK and OT collected data and revised the manuscript. All authors approved the final manuscript as submitted and agree to be accountable for all aspects of the work.

\section{Funding}

The work was supported by JSPS KAKENHI Grant Numbers JP17K09126, JP16KT0009, and JP20K18858. This research was also supported by a grantin-aid from the Ministry of Health, Labour and Welfare, Health and Labour Sciences research grants, Japan (Comprehensive Research on Cardiovascular Disease and Life-Related Disease: H23-Junkankitou [Seishuu]-Ippan-005; H26Junkankitou [Seisaku]-Ippan-001, H29-Junkankitou-Ippan-003 and 20FA1002). The funding sources were independent and had no influence on collection, analysis, and interpretation of data or in writing the manuscript.

\section{Availability of data and materials}

The data that support the findings of this study are available from KENCO study group (Iwate Medical University) but restrictions apply to the availability of these data, which were used under license for the current study, and so are not publicly available. Data are however available from the authors upon reasonable request and with permission of KENCO study group (Iwate Medical University).

\section{Ethics approval and consent to participate}

The research plan was approved by the Ethics Committee of Iwate Medical University Institute Review Board \#1 (approval no. H13-33). The rights and welfare of the participants in this study were protected and the methods were carried out in accordance with the ethical guidelines outlined in the Declaration of Helsinki. Full details of the study were given to the participants, and they agreed and provided written informed consent for participation in this study and publication.

\section{Consent for publication}

Not applicable.

\section{Competing interests}

The authors declare that they have no conflict of interest.

\section{Author details}

'Division of Medical Education, Iwate Medical University, Idaidori 1-1-1, Yahaba-Cho, Shiwa-gun, Iwate 028-3694, Japan. ${ }^{2}$ Department of Health and Welfare, Iwate Prefecture, Morioka, Iwate, Japan. ${ }^{3}$ Takemi Program in International Health, Harvard T.H. Chan School of Public Health, Boston, MA, USA. ${ }^{4}$ Department of Hygiene and Preventive Medicine, Iwate Medical University, Shiwa-gun, Iwate, Japan. ${ }^{5}$ St. Luke's International University, Tokyo, Japan. ${ }^{6}$ Morioka Tsunagi Onsen Hospital, Morioka, Iwate, Japan. ${ }^{7}$ Faculty of Humanities and Social Sciences, Iwate University, Morioka, Iwate, Japan. ${ }^{8}$ Department of Neurology and Gerontology, Iwate Medical University, Shiwa-gun, Iwate, Japan. 9 Department of Neurosurgery, Iwate Medical University, Shiwa-gun, Iwate, Japan. ${ }^{10}$ Division of Nephrology and Hypertension, Department of Internal Medicine, Iwate Medical University, Shiwa-gun, Iwate, Japan. ${ }^{11}$ Iwate Health Service Association, Morioka, Iwate, Japan. ${ }^{12}$ Health Service Center, Iwate University, Morioka, Japan.

${ }^{13}$ Department of Nutritional Sciences, Morioka University, Takizawa, Japan.

${ }^{14}$ Research Institute of Strategy for Prevention, Tokyo, Japan.

Received: 15 March 2020 Accepted: 30 August 2020

Published online: 07 September 2020

\section{References}

1. Jylha M. What is self-rated health and why does it predict mortality? Towards a unified conceptual model. Soc Sci Med. 2009;69(3):307-16.

2. Idler EL, Benyamini Y. Self-rated health and mortality: a review of twentyseven community studies. J Health Soc Behav. 1997;38(1):21-37.

3. van der Linde RM, Mavaddat N, Luben R, Brayne C, Simmons RK, Khaw KT, et al. Self-rated health and cardiovascular disease incidence: results from a longitudinal population-based cohort in Norfolk, UK. PLoS One. 2013;8(6): e65290.

4. Emmelin M, Weinehall L, Stegmayr B, Dahlgren L, Stenlund H, Wall S. Selfrated ill-health strengthens the effect of biomedical risk factors in predicting 
stroke, especially for men -- an incident case referent study. J Hypertens. 2003;21(5):887-96.

5. Tsuji I, Minami Y, Keyl PM, Hisamichi S, Asano H, Sato M, et al. The predictive power of self-rated health, activities of daily living, and ambulatory activity for cause-specific mortality among the elderly: a threeyear follow-up in urban Japan. J Am Geriatr Soc. 1994:42(2):153-6.

6. Idler EL. Age differences in self-assessments of health: age changes, cohort differences, or survivorship? J Gerontol. 1993;48(6):S289-300.

7. Kaplan GA, Camacho T. Perceived health and mortality: a nine-year followup of the human population laboratory cohort. Am J Epidemiol. 1983; 117(3):292-304.

8. Montlahuc C, Soumare A, Dufouil C, Berr C, Dartigues JF, Poncet M, et al. Self-rated health and risk of incident dementia: a community-based elderly cohort, the 3C study. Neurology. 2011;77(15):1457-64.

9. OECD. Elderly population (indicator). OECD Data; 2019. https://data.oecd. org/pop/elderly-population.htm. Accessed 4 June 2019

10. WHO. Countries Japan; 2017. https://www.who.int/countries/jpn/en/. Accessed 4 June 2019

11. Ministry of Internal Affairs and Communications, Japan. Estimated pouration in October 1, 2018. [in Japanese]. Tokyo; 2018. https:/www.stat.go.jp/data/ jinsui/2018np/index.html. Accessed 4 June 2019.

12. Cabinet Office, Government of Japan. Situation on Aging. [in Japanese]. Tokyo; 2016. https://www8.cao.go.jp/kourei/whitepaper/w-2016/html/ zenbun/s1_1_1.html. Accessed 5 June 2019.

13. Ministry of Health, Labour and Welfare, Japan. Health and Medical Services, Overview of the system and the basic statistics. Tokyo; 2017. https://www. mhlw.go.jp/english/wp/wp-hw11/dl/02e.pdf. Accessed 16 Feb 2019.

14. Tsutsui T, Muramatsu N. Care-needs certification in the long-term care insurance system of Japan. J Am Geriatr Soc. 2005;53(3):522-7.

15. Ministry of Internal Affairs and Communications, Japan. Time series of total number of long term care. [in Japanese]. Tokyo; 2016. https://www5.cao.go. jp/keizai-shimon/kaigi/special/reform/wg1/../shiryou3-2-2.pdf. Accessed 4 June 2019.

16. Ogawa Y, Iwasaki K, Yasumura S. A longitudinal study on health status and factors relating to it in elderly residents of a community. [Nihon Koshu Eisei Zasshi] Jpn J Public Health. 1993;40(9):859-71 [in Japanese].

17. Hirosaki M, Okumiya K, Wada T, Ishine M, Sakamoto R, Ishimoto Y, et al. Selfrated health is associated with subsequent functional decline among older adults in Japan. Int Psychogeriatr. 2017;29(9):1475-83.

18. Imuta $\mathrm{H}$, Yasumura $\mathrm{S}$, Ahiko T, Fukao A. Predictors of functional status among independent and homebound community dwelling elderly: physical, psychological, and social parameters. [Nihon Koshu Eisei Zasshi] Jpn J Public Health. 2002;49(6):483-96 [in Japanese].

19. Hirai $\mathrm{H}$, Kondo $\mathrm{K}$, Ojima T, Murata C. Examination of risk factors for onset of certification of long-term care insurance in community-dwelling older people: AGES project 3-year follow-up study. [Nihon Koshu Eisei Zasshi] Jpn J Public Health. 2009:56(8):501-12 [in Japanese].

20. Ashburner JM, Cauley JA, Cawthon P, et al. Self-ratings of health and change in walking speed over 2 years: results from the caregiver-study of osteoporotic fractures. Am J Epidemiol. 2011;173(8):882-9.

21. Lee $Y$. The predictive value of self assessed general, physical, and mental health on functional decline and mortality in older adults. J Epidemiol Community Health. 2000;54(2):123-9.

22. Idler EL, Russell LB. Davis D. survival, functional limitations, and self-rated health in the NHANES I epidemiologic follow-up study, 1992. First National Health and nutrition examination survey. Am J Epidemiol. 2000;152(9):874-83.

23. Idler EL, KasI SV. Self-ratings of health: do they also predict change in functional ability? J Gerontol B Psychol Sci Soc Sci. 1995;50(6):S344-53.

24. Ohsawa M, Itai K, Tanno K, Onoda T, Ogawa A, Nakamura M, et al. Cardiovascular risk factors in the Japanese northeastern rural population. Int J Cardiol. 2009:137(3):226-35

25. Arai $Y$, Zarit SH, Kumamoto $\mathrm{K}$, et al. Are there inequities in the assessment of dementia under Japan's LTC insurance system? Int J Geriatr Psychiatry. 2003:18:346-52

26. Ashida T, Kondo N, Kondo K. Social participation and the onset of functional disability by socioeconomic status and activity type: the JAGES cohort study. Prev Med. 2016;89:121-8

27. Ministry of Health, Labor and Welfare, Japan. The Long-term care Insurance System 2 [Web Page]. Tokyo: Ministry of Health,Labour and Welfare; 2002. [updated July 2002. Available from: http://www.mhlw.go.jp/english/topics/ elderly/care/index.html. Accessed 15 Dec 2016.
28. Campbell JC, Ikegami N. Long-term care insurance comes to Japan. Health Aff (Millwood). 2000;19:26-39 [published Online First: 2000/05/17].

29. Takahashi S, Tanaka F, Yonekura Y, Tanno K, Ohsawa M, Sakata K, et al. The urine albumin-creatinine ratio is a predictor for incident long-term care in a general population. PLoS One. 2018;13(3):e0195013.

30. Tanno K, Ohsawa M, Onoda T, Itai K, Sakata K, Tanaka F, et al. Poor self-rated health is significantly associated with elevated C-reactive protein levels in women, but not in men, in the Japanese general population. J Psychosom Res. 2012;73(3):225-31.

31. Tanaka F, Komi R, Makita S, Onoda T, Tanno K, Ohsawa M, et al. Low-grade albuminuria and incidence of cardiovascular disease and all-cause mortality in nondiabetic and normotensive individuals. J Hypertens. 2016;34(3):506-12.

32. Bando $\mathrm{S}$, Tomata $Y$, Aida J, et al. Impact of oral self-care on incident functional disability in elderly Japanese: the Ohsaki cohort 2006 study. BMJ Open. 2017;7:e017946.

33. Idler EL, Angel RJ. Self-rated health and mortality in the NHANES-I epidemiologic follow-up study. Am J Public Health. 1990;80(4):446-52.

34. Haga H, Shibata H, Suyama Y, Suzuk K, Iwasaki K, Suzuki T, et al. Self-rated health as a predictor of active life in the community elderly. J Epidemiol. 1995:5:11-5

35. Morita T, Okuno T, Himeno T, et al. Glycemic control and disability-free survival in hypoglycemic agent-treated community-dwelling older patients with type 2 diabetes mellitus. Geriatr Gerontol Int. 2017;17:1858-65.

36. Yamada M, Arai H, Nishiguchi S, et al. Chronic kidney disease (CKD) is an independent risk factor for long-term care insurance (LTCI) need certification among older Japanese adults: a two-year prospective cohort study. Arch Gerontol Geriatr. 2013;57:328-32.

37. Lee Y, Shinkai S. A comparison of correlates of self-rated health and functional disability of older persons in the Far East: Japan and Korea. Arch Gerontol Geriatr. 2003:37:63-76.

38. Yamada S, Adachi T, Izawa H, et al. A multicenter prospective cohort study to develop frailty-based prognostic criteria in heart failure patients (FLAG SHIP): rationale and design. BMC Cardiovasc Disord. 2018;18:159.

39. Vidán MT, Blaya-Novakova V, Sánchez E, Ortiz J, Serra-Rexach JA, Bueno H. Prevalence and prognostic impact of frailty and its components in nondependent elderly patients with heart failure. Eur J Heart Fail. 2016;18(7): $869-75$

40. Ullberg T, Zia E, Petersson J, et al. Changes in functional outcome over the first year after stroke: an observational study from the Swedish stroke register. Stroke. 2015;46:389-94.

41. Corso G, Bottacchi E, Giardini G, et al. Epidemiology of stroke in northern Italy: the cerebrovascular Aosta registry, 2004-2008. Neurol Sci. 2013;34: 1071-81.

42. Ministry of Health, Labour and Welfare, Japan. Summary report of comprehensive survey of living conditions 2010. Tokyo; 2010. http://www. mhlw.go.jp/english/database/db-hss/cslc-report2010.html. Accessed 23 June 2017.

43. Møller L, Kristensen TS, Hollnagel H. Self rated health as a predictor of coronary heart disease in Copenhagen, Denmark. J Epidemiol Community Health. 1996;50:423-8.

44. Kubzansky LD, Kawachi I, Spiro A 3rd, et al. Is worrying bad for your heart? A prospective study of worry and coronary heart disease in the normative aging study. Circulation. 1997;95:818-24.

45. Nishiguchi S, Yamada M, Sonoda T, et al. Cognitive decline predicts longterm care insurance requirement certification in community-dwelling older Japanese adults: a prospective cohort study. Dement Geriatr Cogn Dis Extra. 2013;3:312-9.

46. Lin HR, Otsubo T, Imanaka Y. The effects of dementia and long-term care services on the deterioration of care-needs levels of the elderly in Japan. Medicine. 2015:94:e525.

47. Noh J-W, Chang Y, Park M, et al. Self-rated health and the risk of incident type 2 diabetes mellitus: a cohort study. Sci Rep. 2019;9:3697.

48. Tomten SE, Høstmark AT. Self-rated health showed a consistent association with serum HDL-cholesterol in the cross-sectional Oslo health study. Int J Med Sci. 2007:4:278-87.

49. Hoshi R, Tomata Y, Kakizaki M, et al. Serum total cholesterol levels and eligibility for long-term care insurance: a prospective cohort study of the Tsurugaya project. [Nihon Koshu Eisei Zasshi] Jpn J of Public Health. 2013. 60:435-43 [in Japanese].

50. Himeno $T$, Okuno $T$, Watanabe $K$ et al. Range in systolic blood pressure and care-needs certification in long-term care insurance in community-dwelling 
older patients with chronic kidney disease. J Int Med Res. 2018;46(1):293306.

51. Jylhä M, Volpato S, Guralnik JM. Self-rated health showed a graded association with frequently used biomarkers in a large population sample. J Clin Epidemiol. 2006;59:465-71.

52. St John P, Montgomery P. Does self-rated health predict dementia? J Geriatr Psychiatry Neurol. 2013;26(1):41-50.

53. Mehta D, Pimentel DA, Nunez MZ, Abduljalil A, Novak V. Subclinical albuminuria is linked to gray matter atrophy in type 2 diabetes mellitus. Metabolism. 2014;63(11):1390-7.

54. Lekander M, Elofsson S, Neve IM, Hansson LO, Unden AL. Self-rated health is related to levels of circulating cytokines. Psychosom Med. 2004;66(4):559-63.

55. Zuliani G, Guerra G, Ranzini M, Rossi L, Munari MR, Zurlo A, et al. High interleukin-6 plasma levels are associated with functional impairment in older patients with vascular dementia. Int J Geriatr Psychiatry. 2007;22(4): 305-11.

56. Ministry of Internal Affairs and Communications, Japan. Elderly person age 65 years old or older in Japan. [in Japanese]. Tokyo; 2013. http://www.stat. go.jp/data/topics/pdf/topics72.pdf. Accessed 11 Feb 2017.

57. Ministry of Health, Labour and Welfare, Japan. Status report on long-term care insurance. [in Japanese]. Tokyo; 2013. http://www.mhlw.go.jp/topics/ kaigo/osirase/jigyo/13/dl/h25_gaiyou.pdf. Accessed 11 Feb 2017.

58. Ministry of Health, Labour and Welfare, Japan. Summary report of comprehensive survey of living conditions 2004. Tokyo; 2004. https://www. mhlw.go.jp/toukei/saikin/hw/k-tyosa/k-tyosa04/index.html . Accessed 23 June 2017.

\section{Publisher's Note}

Springer Nature remains neutral with regard to jurisdictional claims in published maps and institutional affiliations.

Ready to submit your research? Choose BMC and benefit from:

- fast, convenient online submission

- thorough peer review by experienced researchers in your field

- rapid publication on acceptance

- support for research data, including large and complex data types

- gold Open Access which fosters wider collaboration and increased citations

- maximum visibility for your research: over $100 \mathrm{M}$ website views per year

At BMC, research is always in progress.

Learn more biomedcentral.com/submissions 